\title{
The right answer
}

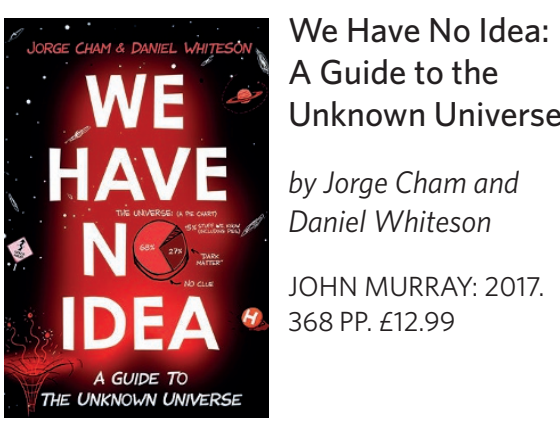

$\mathrm{T}$ here's no shortage of cartoon-illustrated popular science books. You might have read What If? by Randall Munroe, better known as xkcd (John Murray, 2014). My personal favourite is Element Girls - an introduction to the periodic table of elements using manga illustrations (PHP Labs, 2008; in Japanese). But then if Jorge Cham, the creator of PHD comics, takes on such a book project, of course it has to stand out.

Gone are the days when Lord Kelvin would say that there was nothing new to be discovered in physics. But still, the arrogant notion that science has solved it all persisted well into the twentieth century. Only over the past few decades has the scientific community truly come to appreciate how little we actually know about the Universe. As William Phillips put it in an interview a few years ago, "We live in an incredibly exciting time for physics. We don't know what $96 \%$ of the Universe is made of what can be more exciting than that?" (Nature 490, S11-S12; 2012).

Following Cham's previous efforts to bring physics to the masses though PHDlike comics and videos, he has now teamed

\section{PLAUSIBLE THEORIES ABOUT GRAVITY:}

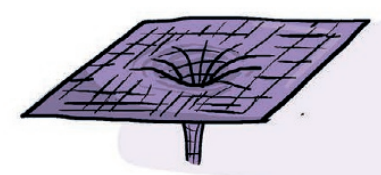

IT'S A DISTORTION OF SPACE-TIME.

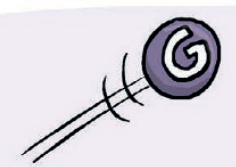

IT'S MEDIATED

BY QUANTUM GRAVITONS.

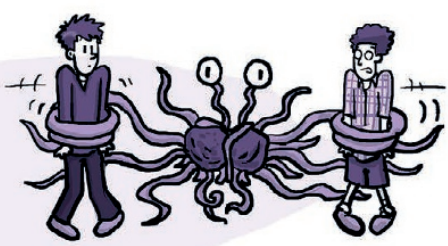

IT'S THE WARM EMBRACE OF THE GIANT SPAGHETT MONSTER. up with CERN physicist Daniel Whiteson to create a book that tries to convey this exact feeling of overwhelming awe and excitement. The book is both accessible and entertaining - and succeeds in popularizing science by trying to explain the enormous challenges modern physics is facing today. In doing so, it also attempts to demystify research to some extent. Scientists no longer hold the answers to everything. Instead they are more like cool, but clueless, explorers trying to map the vastness of the Universe.

In the first few chapters, Cham and Whiteson dive directly into the topics we clearly know the least about: dark matter and dark energy. Then they tackle mass, gravity, time and space. They ask where antimatter might be found, ponder the size of the Universe, and discuss what happened during the Big Bang. Entire tomes could be dedicated to each of these topics, but Cham and Whiteson distil the essence of the little we know - and the lots we have no idea about. Unfortunately, as the book progresses, it loses momentum, and the final chapter on whether there is (intelligent) life in the Universe strikes me as a bit out of place. Yes, it is an exciting topic for the general public, but given the previous chapters I would have expected to learn about the mysteries of black holes, neutrinos or quantum mechanics.

We Have No Idea certainly does stand out, if only for the title. The book is full of humour (and weird pets; no spoiler intended), so it is a very enjoyable read. Some of the cartoons are truly excellent and the physics explanations are just at the right level. After a while I did experience a case of pun overload and the authors themselves seemed aware of overdoing it. I wonder whether general readers might get to the stage where they cannot tell the real fact from the pun any longer. But overall the book manages to convey a very good message to the general public: physics is really cool, precisely because we are still lacking most of the answers.

\section{REVIEWED BY IULIA GEORGESCU}

Corrected online: 7 July 2017

\section{The road to bionic man}

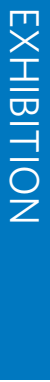

Galileo Galilei is referred to as the father of both modern physics and observational astronomy. His creation of telescopes powerful enough to make astronomical observations, coupled with his use of the scientific method, enabled him to take pioneering steps that transformed our way of thinking: he disproved Aristotle's assertion that heavy objects fall faster than lighter ones, and championed heliocentrism, which landed him with both praise and controversy. What often receives less attention, however, are Galileo's contributions to early compound microscopes, which provided an eyepiece to the microscopic anatomy and mechanisms of life. A new exhibition in his home town of Pisa uses the development of the compound microscope as a starting point to explore how physics has shaped our understanding of the human body and how, along with computer science, it may shape it in the future.

Before entering the exhibition, attendees are met with a small collection of Etruscan surgical instruments, giving an insight into the dental practices of this ancient 


\section{Correction}

In the Books \& Arts 'The right answer' (Nature Physics 13, 527; 2017), the cover image and

publisher were incorrect, as the information for

the UK edition should have been used instead

of the US edition. This has been corrected in the online versions 7 July 2017. 